This article was published in Biofouling, 31(4), 349-362, 2015

http://dx.doi.org/10.1080/08927014.2015.1042873

\title{
Kinetics of biofilm formation by drinking water isolated Penicillium expansum
}

Lúcia Chaves Simões ${ }^{\mathrm{a}, \mathrm{b}_{*}}$, Manuel Simões ${ }^{\mathrm{b}}$ and Nelson Lima ${ }^{\mathrm{a}, \mathrm{c}}$

${ }^{a} C E B$, Centre of Biological Engineering, University of Minho, Braga, Portugal; ${ }^{b} L P A B E$, Faculty of Engineering, Department of Chemical Engineering, University of Porto, Porto,

Portugal; ${ }^{C}$ Postgraduate Program in Agricultural Microbiology, Federal University of Lavras, Lavras, Brazil

Current knowledge on drinking water (DW) biofilms has been obtained mainly from studies on bacterial biofilms. Very few reports on filamentous fungi (ff) biofilms are available, although they can contribute to the reduction in DW quality. This study aimed to assess the dynamics of biofilm formation by Penicillium expansum using microtiter plates under static conditions, mimicking water flow behaviour in stagnant regions of drinking water distribution systems. Biofilms were analysed in terms of biomass (crystal violet staining), metabolic activity (resazurin, fluorescein diacetate and 3-(4,5- dimethyl-2-thiazolyl)-2,5-diphenyl-2H-tetrazolium bromide [MTT]) and morphology (epifluorescence [calcofluor white M2R, FUN-1, FDA and acridine orange] and bright-field microscopies). Biofilm development over time showed the typical sigmoidal curve with noticeable different phases in biofilm formation (induction, exponential, stationary, and sloughing off). The methods used to assess metabolic activity provided similar results. The microscope analysis allowed identification of the involvement of conidia in initial adhesion (4 h), germlings ( $8 \mathrm{~h}$ ), initial monolayers (12 h), a mono- layer of intertwined hyphae (24 h), mycelial development, hyphal layering and bundling, and development of the mature biofilms ( $\geq 48 \mathrm{~h}$ ). P. expansum grows as a complex, multicellular biofilm in $48 \mathrm{~h}$. The metabolic activity and biomass of the fungal biofilms were shown to increase over time and a correlation between metabolism, biofilm mass and hyphal development was found.

Keywords: biofilm analysis; biomass determination; filamentous fungi; metabolic stains; microscopy; microtiter plate

\section{Introduction}

Biofilms are a major microbial problem in drinking water distribution systems (DWDS), contributing significantly to the deterioration of drinking water (DW) quality (Momba et al. 2000; Szewzyk et al. 2000; Berry et al. 2006; Huq et al. 2008). Bacteria are generally dominant in DW biofilms due to their high growth rates, small size, adaptation capacities and ability to produce extra- cellular polymeric substances (EPS) (Characklis \& Marshall 1990; Simões 2013). Filamentous fungi (ff) may also be present (Gonçalves et al. 2006). Fungal contamination of DW has been reported for decades, although investigations have been inadequate compared to those performed with bacteria (Paterson \& Lima 2005; Hageskal et al. 2009). Some of the problems associated with fungal growth in DWDS are unsightly appearance, blocked pipes, odours and tastes, pigments, a source of potentially pathogenic and allergy-causing fungi, and mycotoxin 
production (Paterson \& Lima 2005, 2010; Ribeiro et al. 2006; Hageskal et al. 2009). However, the health problems associated with the presence of fungi in DWDS are still underestimated and not fully understood (Doggett 2000; Paterson \& Lima 2005, 2010; Gonçalves et al. 2006; Hageskal et al. 2009).

Very few reports on filamentous fungal biofilms can be found in the literature, probably because these microorganisms do not fit within restrictive biofilm definitions based on bacteria (Harding et al. 2009; Siqueira et al. 2011). However, fungi are adapted for growth on surfaces, as evidenced by their absorptive nutrition mode, their secretion of extracellular enzymes to digest complex molecules, and apical hyphal growth (Jones 1994). Nevertheless, the term 'biofilm' is still rarely applied to ff. Although the reports on ff biofilms are sparse, there have been several descriptions of biofilm formation in different medical, environmental and industrial settings (Harding et al. 2009). Harding et al. (2009) proposed a preliminary model for filamentous fungal bio- film formation, drawn from bacterial and yeast models, which comprises six steps (propagule adsorption, active attachment to a surface, microcolony formation I, micro- colony formation II or initial maturation, maturation or reproductive development, and a dispersal or planktonic phase). According to these authors all the steps are com- parable to those which occur for bacterial biofilm formation. However, filamentous fungal biofilms are known to have morphological and growth features distinct from both bacterial and yeast biofilms that complicate the understanding of ff biofilms (Harding et al. 2009). In particular, within the asexual phases of the life cycle, ff lack the growth dynamics resulting from binary fission or budding that are common in bacteria and yeasts. Moreover, many ff produce invasive hyphae and/or structures that extend beyond the liquid-air interface, or the specialized structures necessary for host penetration, sporulation, and nutrient acquisition at the host interface (Harding et al. 2009). Fungi are therefore excellent candidates for biofilm formation but this aspect is still poorly understood (Siqueira et al. 2011).

One of the main limitations of fungal water studies is related to the methods used for their detection and quantification. The differences in methods limit the consistency in the studies performed and make direct comparisons almost impossible (Hageskal et al. 2009). Furthermore, there is no quantitative, fast, reliable and standardized method to assess and quantify ff biofilms, or for the determination of fungal viability, especially for those of the filamentous type (Hassan et al. 2002). Another problem is the fact that the pipes in water net- works are often inaccessible, thus in situ approaches are normally scarce and pilot systems in the laboratory are used to enable the removal of pipe samples for analysis (Siqueira et al. 2011). Several laboratory devices have been developed to study biofilms autonomously from DWDS. These devices aim to mimic DWDS behaviour in order to gather results that can be transposed to reality, allowing testing of different conditions and feeding with tap water or appropriate medium/enriched water (Gomes, Simões, et al. 2014).

As ff are part of the microbial ecosystems of DWDS and can contribute to a reduction in DW quality, it is relevant to understand their role in DW biofilm formation and behaviour. Therefore, the purpose of this work was to assess and characterize the kinetics of biofilm formation by Penicillium expansum, a strain isolated from a DWDS. Microtiter plates were used for biofilm formation under controlled static conditions, mimicking the water flow behaviour in stagnant regions of DWDS. Several spectrophotometric methods, commonly used for bacterial biofilms, were used with modifications to quantify fungal biofilm production, in order to fill the gap in quantitative methods to assess ff biofilm formation. The morphology and physiology of ff 
biofilms was also characterized by in situ microscope analysis (epifluorescence and bright-field microscopies).

\section{Materials and methods}

\section{Fungus and culture conditions}

Penicillium expansum MUM 00.02, supplied by the Micoteca da Universidade do Minho fungal culture col- lection (MUM, Braga, Portugal), was used throughout this work and was chosen based on its high occurrence in the tap water of the north of Portugal (Gonçalves et al. 2006). P. expansum was maintained on malt extract agar (MEA: malt extract $20 \mathrm{~g}$, peptone $5 \mathrm{~g}$, agar 20 $\mathrm{g}$, distilled water 11$)$ at $4^{\circ} \mathrm{C}$.

\section{Stock solution of fungal spores}

Spores of P. expansum were harvested from seven-day aged pure cultures in MEA at $25^{\circ} \mathrm{C}$ by flooding the surface of the agar plates with $2 \mathrm{ml}$ of TWS solution $(0.85 \% \mathrm{NaCl}$ plus $0.05 \%$ Tween 80 ) and rocking gently. The suspension was then homogenized by vortexing (Heidolph Reax 2000, Schwabach, Germany) and used for large scale production of spores. The final spore suspension was homogenized by vortexing before quantification using a Neubauer count chamber. Several aliquots of spore suspension with $10 \%$ of glycerol were cryopreserved at $-80^{\circ} \mathrm{C}$ in order to allow the use of the same spore suspension in all the biofilm assays. Stock spore suspensions were resuspended in the volume of R2A broth (yeast extract $0.5 \mathrm{~g}$, proteose peptone $0.5 \mathrm{~g}$, casein hydrolyzate $0.5 \mathrm{~g}$, glucose $0.5 \mathrm{~g}$, soluble starch $0.5 \mathrm{~g}$, dipotassium phosphate 0.3 $\mathrm{g}$, magnesium sulphate $0.024 \mathrm{~g}$, sodium pyruvate $0.3 \mathrm{~g}$, distilled water 11 ) necessary to achieve a density of $10^{5}$ spores $\mathrm{ml}^{-1}$. This was the spore concentration used for biofilm formation assays.

\section{Kinetics of fungal biofilm formation in microtiter plates}

Fungal biofilms were developed according to the modified microtiter plate test previously used by Simões, Simões, and Vieira (2007) to form bacterial biofilms. Briefly, for each condition (different biofilm formation ages) at least 16 wells of sterile polystyrene 96 -well flat tissue culture plates (Greiner Bio-one Cellstar ${ }^{\circledR}$, Krems- münster, Austria) were filled under aseptic conditions with $200 \mu$ of spore suspension ( $10^{5}$ spores $\mathrm{ml}^{-1}$ in R2A broth). Additionally, for the in situ biofilm micro- scope visualizations, $2 \mathrm{ml}$ of spore suspension were added to the wells of a sterile DNAase and RNAase free (Greiner Bio-one Cellstar ${ }^{\circledR}$ ). polystyrene 24-well culture multiwell. To promote biofilm formation, all the plates were incubated aerobically at $25^{\circ} \mathrm{C}$ under static conditions, for 4, 8, 24, 48, 72 and $96 \mathrm{~h}$. At each sampling time, to remove non-adherent and weakly adherent cells, the content of each well was removed and washed three times with $250 \mu 1$ or $2 \mathrm{ml}$ of sterile distilled water for 96- or 24-well plates, respectively. The plates were air dried for $30 \mathrm{~min}$ to remove excess water by evaporation. The remaining attached cells were analysed in terms of biomass adhered on the inner walls of the wells, and in terms of metabolic activity. The rinsing and drying procedures were as previously used with bacterial biofilms (Simões, Simões, Oliveira, et al. 2007; Simões, Simões, \& Vieira 2007; Simões et al. 2010a, 2010b, 2011). However, the reliability of this protocol was also evaluated for the ff biofilms and no interference was detected other than the removal of reversibly adhered cells (results not shown). The morphology of ff biofilms was characterized by microscopy. Negative controls were obtained by incubating the wells only with R2A broth without adding fungal spores. All experiments were 
performed in triplicate with three independent repeats.

\section{Biofilm monitoring by spectrophotometric methods}

Biofilm mass quantification by crystal violet

The biomass adhered on the inner walls of the wells was quantified by the crystal violet (CV) method according to the procedure described by Simões, Simões, and Vieira (2007). The fungal biofilms in the 96 -well plates were fixed with $250 \mu 1$ well $^{-1}$ of $98 \%$ methanol (VWR, Carnaxide, Portugal), for $15 \mathrm{~min}$. Afterwards, the methanol was discarded, the plates left to dry and then the fixed biofilm was stained with $200 \mu$ well $^{-1}$ of CV (Merck, Algés, Portugal) for 5 min. The CV staining protocol was optimized for this fungal strain in terms of CV concentration and the time and temperature of incubation (data not shown). Excess stain was rinsed out by placing the plate under slow running tap water. After this the plates were air dried and the dye bound to the adherent cells was resolubilized by adding $200 \mu \mathrm{well}^{-1}$ of $33 \%(\mathrm{v} / \mathrm{v})$ glacial acetic acid (Panreac, Cascais, Portugal). The optical density of the obtained solution was measured at $570 \mathrm{~nm}$ using a microtiter plate reader (BIO-TEK, Winooski, VT, USA) and the fungal biofilm mass was presented as OD570 $\mathrm{nm}$ values.

\section{Biofilm metabolic activity assessment by resazurin}

Resazurin (7-hydroxy-3H-phenoxazin-3-one-10-oxide) (Sigma-Aldrich, Sintra, Portugal) is a viability dye used to assess the metabolic activity of biofilms (Borges et al. 2012). For each biofilm growth period, fresh R2A broth $(190 \mu \mathrm{l})$ was added to the plates. A volume of $10 \mu \mathrm{l}$ of resazurin $(400 \mu \mathrm{M})$ indicator solution was added to each well, in order to obtain a final concentration $20 \mu \mathrm{M}$ of resazurin. Plates were incubated in the dark for $20-22 \mathrm{~h}$ at $25^{\circ} \mathrm{C}$. The staining protocol was optimized for this fungal strain in terms of stain concentration and the time and temperature of incubation (data not shown). Fluorescence was measured at $\lambda$ excitation $=$ $530 \mathrm{~nm}$ and $\lambda$ emission $=590 \mathrm{~nm}$ using a microtiter plate reader (BIO-TEK).

\section{Biofilm metabolic activity assessment by fluorescein diacetate}

A stock solution ( $2 \mathrm{mg} \mathrm{ml}^{-1}$ in acetone) of 3',6'-diacetyl-

fluorescein, fluorescein diacetate (FDA) (Sigma-Aldrich, Sintra, Portugal) was stored at $-20^{\circ} \mathrm{C}$, and protected from light. For each biofilm growth period, $200 \mu 1$ of FDA diluted in R2A broth were added to each well, in order to obtain a final FDA concentration of $0.08 \mathrm{mg} \mathrm{ml}^{-1}$. The microtiter plates were then incubated in the dark for $20-22 \mathrm{~h}$ at $25^{\circ} \mathrm{C}$. The FDA staining protocol was optimized for this fungal strain in terms of stain concentration and the time and temperature of incubation (data not shown). Fluorescence was measured at $\lambda$ excitation $=485 \mathrm{~nm}$ and $\lambda$ emission $=528 \mathrm{~nm}$ using a microtiter plate reader (BIO- TEK).

\section{Biofilm metabolic activity assessment by tetrazolium bromide (MTT)}

The 3-(4,5-dimethyl-2-thiazolyl)-2,5-diphenyl-2H-tetrazolium bromide (MTT) colorimetric method was applied to determine the fungal activity of the biofilms as described previously (Dias et al. 1999; Siqueira \& Lima 2013) with some modifications. A stock solution of MTT (SigmaAldrich) $\left(5 \mathrm{mg} \mathrm{ml}^{-1}\right.$ in sterile ultrapure water) was aseptically prepared and stored at $4{ }^{\circ} \mathrm{C}$ in a 
dark screw-cap container. For each biofilm formation period, $200 \mu \mathrm{l}$ of MTT diluted in R2A broth were added to each well, in order to obtain a final MTT concentration of $0.5 \mathrm{mg} / \mathrm{ml}^{-1}$. Then, the microtiter plates were incubated for $20-22 \mathrm{~h}$ at $25^{\circ} \mathrm{C}$, in the dark. The MTT staining protocol was optimized for this fungal strain in terms of stain concentration and the time and temperature of incubation (data not shown). After this period, the supernatant was discarded and $200 \mu 1$ dimethyl sulfoxide (DMSO) (Sigma-Aldrich) were added to each well to solubilize the MTT, which had been cleaved into an insoluble purple formazan through the metabolism of the live cells. The microtiter plates were then incubated in the dark, at $25^{\circ} \mathrm{C}$, for 15 min and under agitation $(150 \mathrm{rpm})$ to recover the formazan. The formazan extraction proto- col with DMSO was optimized for this fungal strain in terms of agitation speed and the time and temperature of incubation (data not shown). The optical density of the solubilized formazan of each well was measured at $570 \mathrm{~nm}$ using a microtiter plate reader (BIO-TEK).

\section{Biofulm monitoring by microscopy}

\section{Epifluorescence microscopy}

At each sampling time, a small square of the bottom of each well of 24-well microtiter plates was cut off and the biofilms were inspected by an Olympus BX51 epi- fluorescence microscope (Olympus, Tokyo, Japan) with different stains: calcofluor white M2R (CW) (Invitrogen/ Molecular Probes, Leiden, the Netherlands), FUN-1 (In- vitrogen/Molecular Probes), and FDA and acridine orange (AO) (Sigma-Aldrich). Washed biofilms were stained with $15 \mu 1$ of $25 \mu \mathrm{M}$ of $\mathrm{FUN}-1$ at $30^{\circ} \mathrm{C}$ for $30 \mathrm{~min}$ and $10 \mu \mathrm{l}$ of $25 \mu \mathrm{M} \mathrm{CW}$ at room temperature for $15 \mathrm{~min}$, in the dark. Other fluorochrome combinations were tested, namely FDA with CW, and AO with CW. In this case, washed biofilms were stained with $15 \mu 1$ of FDA $\left(0.05 \mathrm{mg} \mathrm{l}^{-1}\right)$ plus $10 \mu 1$ of 25

$\mu \mathrm{M} \mathrm{CW}$; or $15 \mu 1$ of $\mathrm{AO}\left(0.04 \mathrm{mg} \mathrm{l}^{-1}\right)$ plus $10 \mu \mathrm{l}$ of $25 \mu \mathrm{M} \mathrm{CW}$, at room temperature for $15 \mathrm{~min}$, in the dark. After staining biofilm samples were observed under an epifluorescence micro- scope using UV light equipped with $10 \times / 0.30$ and $40 \times / 0.75$ objective lenses. The optical filter combinations used for FUN-1, FDA and AO were a 470-490 nm excitation filter, a LP516 nm emission filter and a $500 \mathrm{~nm}$ barrier filter and for $\mathrm{CW}$ were a 365-370 nm excitation filter, a LP421 nm emission filter and a $400 \mathrm{~nm}$ barrier filter. The biofilm images were acquired with a microscope camera (Olympus) using the CellB software.

\section{Bright-field microscopy}

Visualization of the washed fungal biofilms was also per- formed using a stereo microscope Leica MZ 125 (Leica Microsystems, Wetzlar, Germany) coupled with a Leica EC3 camera (Leica Microsystems) and LAS EZ image acquisition software (Leica Microsystems). This type of microscopy allows a broad inspection of biofilm samples for their morphology and cell physiology.

\section{Statistical analysis}

The data were analysed using the statistical program SPSS (Statistical Package for the Social Sciences, Armonk, NY, USA) version 20.0. The mean and standard deviation (SD) within samples were calculated for all cases. The data were analysed by the nonparametric Wilcoxon test based on a confidence level of $\geq 95 \%$ ( $p<0.05$ was considered statistically significant). 


\section{Results}

\section{Mass and metabolic activity of ff biofilms}

The results of biofilm accumulation of $P$. expansum over time (using the standard 96-well microtiter plates) obtained by different methods of quantification (CV, resazurin, FDA, and MTT staining) are presented in Figures 1 and 2. The biofilm mass (Figure 1) and metabolic activity (Figure 2) results were correlated $(p>0.05)$, ie an increase in biofilm mass productivity corresponded to increased biofilm metabolic activity. Also, the different methods used to assess the metabolic activity of biofilms provided comparative results $(p>0.05)$ (Figure 2$)$. The analysis of fungal biofilm formation over time showed the typical sigmoidal curve of biofilm formation with minor differences between the several methods used (Figures 1 and 2). It was possible to distinguish the different phases of biofilm formation (induction, exponential, stationary, and sloughing off). The induction phase of P. expansum biofilm formation was identified between 4 and $12 \mathrm{~h}$ for metabolic activity assessed with FDA and MTT (Figure 2), and for biofilm mass evaluated by CV staining (Figure 1). This phase was not detected by the resazurin method (Figure 2), apparently due to the lower detection limit of this method. In this case, biofilm analysis should be per- formed between 0 and $4 \mathrm{~h}$ in order to detect the induction phase. The exponential phase was detected between 12 and $72 \mathrm{~h}$ for CV (Figure 1), 4 to $24 \mathrm{~h}$ for resazurin (Figure 2), and 12 to $48 \mathrm{~h}$ for FDA and MTT (Figure 2). The stationary phase of biofilm growth was identified at 72 to $96 \mathrm{~h}$ for CV (Figure 1), 24 to $96 \mathrm{~h}$ for resazurin (Figure 2), 48 to $96 \mathrm{~h}$ for FDA (Figure 2) and 48 to $72 \mathrm{~h}$ for MTT (Figure 2). In addition, during the time of the biofilm formation experiment $(96 \mathrm{~h})$ it was possible to clearly detect significant biofilm sloughing off with MTT staining (72 to $96 \mathrm{~h}$ ). However, sloughing off was also detected by the other methods for longer biofilm formation periods (results not shown).

\section{Microscope visualizations of ff biofilms}

The morphology of fungal biofilms and the physiology of cells were characterized over time by epifluorescence (using diverse stains, CW, FUN-1, FDA and AO) and bright-field microscopies. Figure 3 shows epifluorescence photomicrographs of spores adhered $(8 \mathrm{~h})$ to polystyrene with several fluorochrome combinations (CW plus FUN-1, CW plus FDA, and CW plus AO). The use of different fluorochrome combinations contributes to the understating of the combination which allows the visualization of the ff biofilm formation process with the highest accuracy. $\mathrm{CW}$ and AO staining gave information on the total fungal biofilm (viable and nonviable), while FUN-1 and FDA provided information only on the viable biofilm population. The combination of CW with FUN-1 and FDA allows the differentiation of viable populations in the biofilm. Figure 3 also shows that the majority of adhered fungal spores were in a viable state (Figure 3A and B), although it is not possible to see the red CIVS (cylindrical intra vacuolar structures) with FUN-1 (Figure 3A). AO staining did not give additional information compared to $\mathrm{CW}$ (Figure 3C).

The different stages of $P$. expansum biofilm development over time were also assessed by epifluorescence and bright-field microscopy and are depicted in Figures 4 and 5, respectively. These microscope images are representative of the overall biofilm development process. Since different combinations of dyes provided similar information, only the CW plus FUN-1 results are presented (Figure 4). The microscope analysis of ff biofilms (Figures 4 and 5) showed the involvement of conidia in initial adhesion $(4 \mathrm{~h})$, with further germling formation $(8 \mathrm{~h})$, the initial monolayer formation (12 h), the monolayer of intertwined hyphae (24 h), mycelial development, 
hyphal layering, hyphal bundling, and development of the mature biofilm ( $>48 \mathrm{~h})$. Comparison between Figures 4 and 5 provides information on the morphology and metabolic state of $\mathrm{ff}$ biofilms by FUN-1 staining and it is possible to see that over time all $\mathrm{ff}$ biofilms were metabolically active. However, it was not possible to see clearly the red CIVS in all samples (Figure 4). Only in mature biofilms was it possible to see the red CIVS with FUN-1 (Figure 4E, $\mathrm{F}$ and G). However, the red CIVS were more evident at $48 \mathrm{~h}$ (Figure 4E), apparently due to the greater amount of layered hyphal bundling in older biofilms hindering visualization of individual cell structures. On the other hand, Figure 5 gives a wider overview of biofilm morphology over time.

\section{Discussion}

The dynamics of microbial growth in DW networks is very complex, as a large number of interacting processes (physico-chemical and biological) are involved. DW bio- films are constituted of a microbial community adapted to conditions of low nutrient concentration and high disinfectant levels. These biofilms are composed of complex microbial communities (bacteria, viruses, protozoa, fungi and algae), functionally organized and embedded in a gelatinous matrix of extracellular polymers excreted by microorganisms (Characklis \& Marshall 1990; Codony et al. 2003; Gonçalves et al. 2006; Snelling et al. 2006). Recent findings into the microbial ecology of DWDS have found that the resistance of pathogens to chlorination is affected by microbial community diversity and interspecies relationships (Berry et al. 2006; Simões et al. 2010b). However, this information was obtained from studies with bacteria. Very few reports on filamentous fungal biofilms can be found in the literature, probably because these microorganisms cannot be fitted completely within restrictive biofilm definitions based on bacteria (Harding et al. 2009; Siqueira et al. 2011). Fungi, as eukaryotic organisms, have peculiar characteristics such as nutrition by heterotrophic absorption, development of reproductive and vegetative structures (ie spores and hyphae), and sexual and asexual reproduction (Siqueira \& Lima 2013). Furthermore, ff biofilms are common in environments exposed to high moisture with a major air interface (ie unsaturated environments) (Holden 2001). In addition, ff often show invasive growth, by penetrating the substrata on which they grow (Gulis et al. 2008). These differences in morphology and growth complicate the understanding on ff biofilm formation and behaviour. Therefore, a direct comparison with the dynamics of bacterial biofilms can provide inaccurate conclusions. According to Harding et al. (2009) it is important to highlight that the unique features related to fungal biology that distinguish bacterial from fungal biofilm formation are due to the ability of fungi commonly to have more than one planktonic form (ie sexual and asexual spores, sporangia, and hyphal fragments). These dispersive forms are not unicellular and often float in air rather than water, and the development of specialized reproductive tissues to produce dispersive forms occurs in fungi in response to specific environmental cues, biological stimuli or stresses (Harding et al. 2009). Another interesting aspect of fun- gal biology that has no counterpart in bacterial biofilms is the aerial component of lifestyle in many species, with a strong dependency on aerial spore dissemination for dispersal (Wösten 2001; Harding et al. 2009). Fungal aerial morphogenesis involves the secretion of small proteins (hydrophobins). The hydrophobins are exclusive to $\mathrm{ff}$ and play a role in several processes in the growth and development of these microorganisms (formation of aerial structures, attachment of hyphae to hydrophobic sur- faces, and changes in hyphal surface properties in response to environmental and developmental cues) (Wösten 2001; Harding et al. 2009). Furthermore, research on ff has 
been hampered by nonstandard methods, difficulties in quantification and a lack of mycological expertise compared with bacteria. In order to improve knowledge on ff biofilm development and behaviour, accurate and reliable methods for their formation and analysis are required.

Since DWDS are complex systems and the pipes are often inaccessible, biofilm studies in situ are not com- mon. In order to study DW biofilms independently from DWDS several laboratorial devices have been developed (annular reactor, concentric cylinder reactor, propella ${ }^{\circledR}$ reactor, flow cell, rotating disc reactor, CDC biofilm reactor) as recently reviewed by Gomes, Simões, et al. (2014). These devices aim to mimic DWDS environments, allowing testing under different conditions (Gomes, Simões, et al. 2014). Several in vitro models have been used to elucidate the developmental stages and processes required for biofilm formation. Microtiter plates are nowadays the most frequently used reactor for studying biofilm formation under strictly laboratorial conditions, including with DW microorganisms (Gomes, Simões, et al. 2014). Moreover, these systems are consistently being applied to form biofilms under conditions that simulate diverse environmental systems, from environment to biomedical (Gomes, Moreira, et al. 2014). These can be used as a rapid, robust and simple method for screening simultaneously the effect of numbers of different parameters on biofilm formation (Simões, Simões, \& Vieira 2007; Simões et al. 2010b, 2011), since equivalent biofilms can be produced at the same time. This reactor has the obvious advantage of allowing high-throughput analysis including the use of noninvasive tests using microscopy (Bridier et al. 2013). It needs only a small space to operate and the control of environmental conditions is easy. However, the main disadvantages are the significant limitations to reproducing the conditions found in a DWDS, particularly the hydrodynamic conditions. Microtiter plates are not flow- through systems. These can only operate under batch or fed-batch conditions and only low hydrodynamic shear stress can be reproduced (Gomes, Simões, et al. 2014). However, polystyrene microtiter plates are commonly used as the standard bioreactor system for adhesion and biofilm formation by bacteria isolated from many different environments, providing reliable comparative data (Simões et al. 2010a; Gomes, Moreira, et al. 2014; Gomes, Simões, et al. 2014). Similarly to other studies, polystyrene was used as a model surface for adhesion and biofilm formation under laboratorial conditions (Simões, Simões, \& Vieira 2007; Pompilio et al. 2008; Johansen et al. 2009). Moreover, polystyrene has physico-chemical sur- face properties (hydrophobicity) similar to those of other materials used in water distribution systems such as stain- less steel and polyvinylchloride (Simões, Simões, Oliveira, et al. 2007). Therefore, microtiter plates were selected to study biofilm formation and behaviour by P. expansum, a strain isolated from DW (Gonçalves et al. 2006), under wellcontrolled static conditions. Regions of stagnant water or low shear stress conditions are common in DWDS, particularly in reservoirs, household pipes, dead zones, corners and valves. These regions are associated with zones of high organic material sedimentation and consequently, abundant biofilm formation (Simões \& Simões 2013). Moreover, unsteady hydraulic conditions can cause water stagnation in DWDS and these promote bacterial accumulation, either in the sessile or planktonic state, thereby compromising biological quality as described by Manuel et al. (2010). Additionally, Sammon et al. (2011) reported that significant vegetative growth and sporulation of filamentous microfungi occur in soft sediments in the pipe dead ends of DWDS.

Filamentous fungal biofilms, like those of bacteria, have defined developmental phases that include arrival at an appropriate substratum, adhesion, colonization, extra- cellular polymer production, and biofilm maturation and dispersal (Chandra et al. 2001; Blankenship \& Mitchell 
2006; Ramage et al. 2011). The cell-substratum and cell-cell interactions, hyphal differentiation and extra- cellular matrix production are key steps in fungal biofilm development (Blankenship \& Mitchell 2006). Quorum sensing might be an important factor in dispersal of bio- film cells (Blankenship \& Mitchell 2006). The adhesion process of ff (spore adhesion) as for bacteria has been described as a two-step process, comprising the initial attachment of ungerminated conidia followed by further adhesion of the developing germtubes and growing hyphae (Priegnitz et al. 2012). Spores, hyphal fragments and other fungal propagules can be functionally equiva- lent to planktonic bacterial cells even if ff do not generally exist as single cells (Harding et al. 2009). However, according to Doggett (2000), spores, not hyphae or vegetative cells, comprise the primary source of viable propagules. This statement was taken into account in performing this study, ie the starting inoculum for bio- film formation kinetics was $P$. expansum spores.

Moreover, the spore seeding density is an important factor in spore adhesion, the germination of the adhered spores and biofilm development of ff as reported on studies with biofilms of Aspergillus fumigatus (Mowat et al. 2007), A. niger (Villena \& Gutierrez-Correa 2007), Trichosporon asahii (Di Bonaventura et al. 2006) and Rhizopus oryzae (Singh et al. 2011). The overall structural morphology and integrity of biofilms is dependent on the concentration of conidia (Mowat et al. 2007). This phenomenon has been found previously in Candida albicans biofilm development (Ramage et al. 2001). Therefore, the spore inoculum density $\left(10^{5}\right.$ spores $\mathrm{ml}^{-1}$ ) of $P$. expansum used was based on previous studies showing the existence of an optimal concentration of spores to obtain robust filamentous biofilms. Very high seeding densities result in poor germination of adhered spores while a low inoculum concentration produces reduced hyphal density (Mowat et al. 2007; Singh et al. 2011).

The several spectrophotometric methods used in this work to quantify filamentous fungal biofilm formation have been extensively used to study bacterial and yeast biofilms in microtiter plates (Pitts et al. 2003; Romanova et al. 2007; Peeters et al. 2008; Mariscal et al. 2009). However, their application in the study of ff biofilms is scarce. On the other hand, the microscope techniques used in this work enabled the qualitative assessment over time of the morphology of ff biofilm development on polystyrene. Microscopy is the only technique whereby fungal morphology and its cellular structures can be studied. For instance, light microscopy (bright-field and fluorescent) is regularly used to obtain rapid, inexpensive qualitative and quantitative information on fungal cells (Ahmad \& Khan 2012). In spite of confocal laser scanning microscopy (CLSM) having a clear advantage in allowing a 3-D characterization of biofilm structure, it is still much more expensive compared to fluorescence microscopy. Therefore, epifluorescence microscopy was used as a first approach to analyse major morphological and physiological aspects of $P$. expansum biofilm development over time. Moreover, comparing with previous studies (Villena et al. 2010; Mukherjee et al. 2012; Amadio et al. 2013), it is not clear that CLSM provides better evidence of filamentous fungal biofilm development than those presented in this study.

As biofilms are very complex microbial communities, their study requires multiple approaches which are able to characterize their different aspects. Methods aimed at analysing filamentous fungal biofilm formation and development are not yet standardized. In this study the kinetics of P. expansum biofilm formation on polystyrene surfaces over $96 \mathrm{~h}$ was assessed by biomass (CV) and metabolic activity (resazurin, FDA and MTT) measurements, and also by microscopy. A correlation between biomass, metabolism and filamentous fungal biofilm development was found for most of the biofilm ages. The biomass and metabolic activity of biofilms were shown to increase over time by the selected methods. CV staining is one of the first methods adopted for 
bio- film biomass quantification. $\mathrm{CV}$ binds to negatively charged microorganisms and polysaccharides of the EPS. The amount of dye solubilized by the solvent is directly proportional to biofilm size (Pantanella et al. 2013). The main limitation of the CV staining assay is related to the low reproducibility of the method. Moreover, because both living and dead cells as well as biofilm matrix components are stained by $\mathrm{CV}$, this method provides no information on the number and viability of cells. Thus, a complementary method to assess the viability of biofilms must be used. Several metabolic methods were used to assess the metabolic activity of biofilms formed by ff. Overall, these different methods gave comparable results. The resazurin assay was the most sensitive method, able to detect lower numbers of active cells. Resazurin is a blue non-fluorescent dye (water-soluble, stable, non-toxic and permeable through cell membranes) that is reduced to the pink-colored, highly fluorescent resorufin. This acts as an intermediate electron acceptor in the electron transport chain without interference by the normal transfer of electrons (Rampersad 2012). The resazurin assay was previously applied to determine the activity of bio- film cells as reported by Sarker et al. (2007) and was described as a reliable and reproducible method for evaluating biofilm susceptibility to antimicrobials (Pettit et al. 2009). However, this assay is highly dependent on cell respiratory efficiency, which in turn is related to the growth phase, and to the age and thickness of the bio- film (Pantanella et al. 2013). Moreover, as the time of resazurin reduction is species- and strain-related, some experimental conditions are difficult to standardize (Pantanella et al. 2013). The main advantage of the resazurin assay is that, being a biological dye, it is non-toxic to cells. The FDA staining assay is not widely used although it is easy to perform and not expensive. FDA (a nonpolar and non-fluorescent substance) is hydrolyzed by intracellular nonspecific esterase in live cells to pro- duce fluorescein, which then exhibits a bright green fluorescence. Esterase activity is required for the accumulation of intracellular fluorescein, and cell mem- brane integrity is required for the intracellular retention of these fluorescent products (Hassan et al. 2002). There- fore, only the cells that have intact membrane and esterase activity are able to accumulate the fluorescent probe (Breeuwer \& Abee 2000). Indeed, the measurement of FDA hydrolysis has been used to estimate biomass activity, also referred to as cell esterase activity (Hassan et al. 2002). According to Pantanella et al. (2013), considering the limited field of examination and the thickness of a biofilm, this method is not particularly suitable for quantitative studies on mature biofilms, yielding only semiquantitave results. However, such a limitation was not found in this study for the $96 \mathrm{~h} f f$ biofilms. The MTT staining assay has been successfully applied to determine the metabolic activity of fungal biofilms (Siqueira \& Lima 2013). MTT is a yellow soluble tetrazolium salt that is converted into an insoluble purple crystal by metabolically active cells. The MTT assay may be affected by the complexity and heterogeneity of the biofilm structure and composition, with different metabolic gradients, by diffusion limitation through a mature biofilm, slowing down or partially retaining the reduction and release of MTT and formazan, respectively (Pantanella et al. 2013). This effect can help to explain the sharp decrease in the metabolic activity of the $96 \mathrm{~h}$ biofilms when assessed by MTT staining.

In addition, the morphology and physiology of fun- gal biofilms were assessed over time by epifluorescence (using diverse stains) and bright-field microscopies. CW stain allows the morphological characterization of the cell walls of fungi because of its affinity for the $\beta(1-3)$ and $\beta(1-4)$ polysaccharides in cellulose, carboxylated polysaccharides and chitin (Siqueira et al. 2011, 2013). FUN-1, FDA and AO as metabolic indicator stains provide information on the viability of fungal biofilms (Hassan et al. 2002; Hua et al. 2011; Siqueira et al. 2011). The results 
of the combination of CW with FUN- 1 and FDA allowed the distinction of a viable population in the biofilm. FUN-1 stain is a membrane-permeant, halogenated cyanine compound that binds to nucleic acids (Hua et al. 2011). FUN-1 staining discriminates dead fungal cells which have a diffuse yellow-green fluorescence, from the metabolically active cells which have red cylindrical intravacuolar structures (CIVS) (Siqueira et al. 2011). The formation of CIVS requires ATP (Hua et al. 2011). However, the results show that despite most biofilms being in a viable state (as shown by FDA staining) at different ages, it was not always possible to see the CIVS with FUN-1. According to the manufacturer's instructions, the visualization of CIVS is a very sensitive process affected by several factors, particularly the con- centration of a readily metabolizable substrate in the culture medium, the dye concentration, the cell density and temperature. FDA, as mentioned previously, is a cell- permeant esterase substrate that can serve as a viability probe to measure both enzymatic activity, which is required to activate its fluorescence, and cell-membrane integrity, which is required for intracellular retention of the fluorescent product. Regarding AO staining, the results obtained did not give additional information com- pared to CW (all biofilm samples were green only, and no red fluorescence was detected, even if the biofilms were in a viable state). AO is a metachromatic dye which differentially stains double-stranded (ds) and single-stranded (ss) nucleic acids. When AO intercalates into dsDNA it emits a green fluorescence. Conversely, it emits a red fluorescence when it interacts with ssDNA or RNA. This unique characteristic makes AO useful for analysis of cellular physiology and cell-cycle studies (Schwartz et al. 1977; Traganos et al. 1977).

The microscopic inspections of P. expamsum biofilm development are representative of the overall biofilm development process. This information has potential scientific interest, taking into account that studies on ff biofilms are scarce. To the authors' knowledge this is the first approach to characterizing the dynamics of biofilm formation by DW-isolated $P$. expansum. Microscope analysis revealed that $P$. expansum spores had adhered on the polystyrene surfaces at $4 \mathrm{~h}$ and showed germ tube formation at $8 \mathrm{~h}$. They started germinating at $12 \mathrm{~h}$, and at this time it was possible to see small hyphal development. By the kinetics of biofilm formation it was possble to verify that the lag phase in biofilm development was at $\sim 12 \mathrm{~h}$. After that, the hyphae began to intertwine, forming a monolayer at $24 \mathrm{~h}$, followed by increased structural complexity leading to mature biofilms at $48 \mathrm{~h}$. This pattern roughly resembles the development kinetics of C. albicans, $A$. niger, A. fumigatus and $R$. oryzae biofilm growth, in terms of the phase and associated morphologies (Ramage et al. 2001; Mowat et al. 2007; Villena \& Gutierrez-Correa 2007; Singh et al. 2011). Filamentous growth was not observed until $12 \mathrm{~h}$ incubation. This was followed by an exponential increase in biofilm biomass (hyphae and EPS) and cellular activity (metabolism). Mature biofilms were found in $48 \mathrm{~h}$. CW staining images and bright-field microscope inspections showed the presence of EPS. After biofilm formation for $48 \mathrm{~h}$, a coordinated network of hyphae was observed, growing in all directions, crossing each other, and being embedded in some areas within a matrix of EPS, and comprising the ultrastructure of a mature biofilm. The development of P. expansum biofilms was slower than that of A. fumigatus (Mowat et al. 2007). Nevertheless, the overall characteristics of development were very similar. The slower development is probably related to the differences between the two genera and the culture conditions selected.

Overall, this study demonstrates that $P$. expansum grows as a complex, multicellular biofilm in $48 \mathrm{~h}$. Simi- lar to bacterial biofilms, it was possible to identify the different phases of ff biofilm formation. It was also possible to apply several quantitative methods, previously used with 
bacterial biofilms, to study filamentous fungal biofilms. The metabolic activity and biomass of the fungal biofilms were found to increase over time. It was possible to show a correlation between metabolism, biofilm mass and hyphal development using the selected methods.

\section{Conflict of interest disclosure statement}

No potential conflict of interest was reported by the authors.

\section{Funding}

Lúcia C. Simões acknowledges the grant provided by the Portuguese Foundation for Science and Technology (FCT), under Grant no. [SFRH/BPD/81982/2011].

\section{References}

Ahmad I, Khan MSA. 2012. Microscopy in mycological research with especial reference to ultrastructures and bio- film studies. In: Méndez-Vilas A, editor. Current microscopy contributions to advances in science and technology. Spain: Formatex Research Centre; p. 646-659.

Amadio J, Casey E, Murphy CD. 2013. Filamentous fungal biofilm for production of human drug metabolites. Appl Microbiol Biotechnol. 97:5955-5963.

Berry D, Xi C, Raskin L. 2006. Microbial ecology of drinking water distribution systems. Curr Opin Biotechnol. 17:297- 302.

Blankenship JR, Mitchell AP. 2006. How to build a biofilm: a fungal perspective. Curr Opin Microbiol. 9:588-594.

Borges A, Saavedra MJ, Simões M. 2012. The activity of ferulic and gallic acids in biofilm prevention and control of pathogenic bacteria. Biofouling. 28:755-767.

Breeuwer P, Abee T. 2000. Assessment of viability of microorganisms employing fluorescence techniques. Int J Food Microbiol. 55:193-200.

Bridier A, Meylheuc T, Briandet R. 2013. Realistic representation of Bacillus subtilis biofilms architecture using combined microscopy (CLSM, ESEM and FESEM). Micron. 48:65-69.

Chandra J, Kuhn DM, Mukherjee PK, Hoyer LL, McCormick T, Ghannoum MA. 2001. Biofilm formation by the fungal pathogen Candida albicans: development, architecture, and drug resistance. J Bacteriol. 183:5385-5394.

Characklis WG, Marshall KC. 1990. Biofilms: a basis for an interdisciplinary approach. In: Characklis WG, Marshall KC, editors. Biofilms. New York (NY): Wiley; p. 3-15.

Codony F, Miranda AM, Mas J. 2003. Persistence and proliferation of some unicellular algae in drinking water systems as result of their heterotrophic metabolism. Water SA. 29:113-116.

Dias N, Nicolau A, Carvalho GS, Mota M, Lima N. 1999. Miniaturization and application of the MTT assay to evaluate metabolic activity of protozoa in the presence of toxicants. J Basic Microbiol. 39:103-108.

Di Bonaventura G, Pompilio A, Picciani C, Iezzi M, D'Antonio D, Piccolomini R. 2006. Biofilm formation by the emerging fungal pathogen Trichosporon asahii: development, architecture, and antifungal resistance. Antimicrob Agents Chemother. 50:3269-3276.

Doggett MS. 2000. Characterization of fungal biofilms within a municipal water distribution system. Appl Environ Micro- biol. 66:1249-1251.

Gomes IB, Simões M, Simões LC. 2014. An overview on the reactors to study drinking water 
biofilms. Water Res. 62:63-87.

Gomes LC, Moreira JM, Teodósio JS, Araújo JD, Miranda JM, Simões M, Melo LF, Mergulhão FJ. 2014. 96-well microtiter plates for biofouling simulation in biomedical settings. Biofouling. 30:535-546.

Gonçalves AB, Paterson RM, Lima N. 2006. Survey and significance of filamentous fungi from tap water. Int J Hyg Environ Health. 209:257-264.4.

Gulis V, Suberkropp K, Rosemond AD. 2008. Comparison of fungal activities on wood and leaf litter in unaltered and nutrient-enriched headwater streams. Appl Environ Micro- biol. 74:1094-1101.

Hageskal G, Lima N, Skaar I. 2009. The study of fungi in drinking water. Mycol Res. 113:165172.

Harding MW, Marques LLR, Howard RJ, Olson ME. 2009. Can filamentous fungi form biofilms? Trends Microbiol. 17:475-480.

Hassan M, Corkidi G, Galindo E, Flores C, Serrano-Carreo L. 2002. Accurate and rapid viability assessment of Tricho- derma harzianum using fluorescence-based digital image analysis. Biotechnol Bioeng. 80:677-684.

Holden PA. 2001. Biofilms in unsaturated environments. Meth- ods Enzymol. 337:125-143.

Hua SST, Brandl MT, Hernlem B, Eng JG, Sarreal SBL. 2011. Fluorescent viability stains to probe the metabolic status of aflatoxigenic fungus in dual culture of Aspergillus flavus and Pichia anomala. Mycopathologia. 171:133-138.

Huq A, Whitehouse CA, Grim CJ, Alam M, Colwell RR. 2008. Biofilms in water, its role and impact in human dis- ease transmission. Curr Opin Biotechnol. 19:244-247.

Johansen TB, Agdestein A, Olsen I, Nilsen SF, Holstad G, Djønne B. 2009. Biofilm formation by Mycobacterium avium isolates originating from humans, swine and birds. BMC Microbiol. 9:159.

Jones JBG. 1994. Fungal adhesion. Mycol Res. 98:961-981.

Manuel CM, Nunes OC, Melo LF. 2010. Unsteady state flow and stagnation in distribution systems affect the biological stability of drinking water. Biofouling. 26:129-139.

Mariscal A, Lopez-Gigosos RM, Carnero-Varo Fernandez- Crehuet J. 2009. Fluorescent assay based on resazurin for detection of activity of disinfectants against bacterial biofilm. App Microbiol Biotechnol. 82:773-783.

Momba M, Kfir R, Venter SN, Cloete TE. 2000. An overview of biofilm formation in distribution systems and its impact on the deterioration of water quality. Water SA. 26:59-66.

Mowat E, Butcher J, Lang S, Williams C, Ramage G. 2007. Development of a simple model for studying the effects of antifungal agents on multicellular communities of Aspergillus fumigatus. J Med Microbiol. 56:1205-1212.

Mukherjee PK, Chandra J, Yu C, Sun Y, Pearlman E, Ghannoum MA. 2012. Characterization of Fusarium keratitis outbreak isolates: contribution of biofilms to antimicrobial resistance and pathogenesis. Invest Ophthalmol Vis Sci. 53:4450-4457.

Pantanella F, Valenti P, Natalizi T, Passeri D, Berlutti F. 2013. Analytical techniques to study microbial biofilm on abiotic surfaces: pros and cons of the main techniques currently in use. Ann Ig. 25:31-42.

Paterson RR, Lima N. 2005. Fungal contamination of drinking water. In: Lehr J, Keeley J, Lehr J, Kingery TB III, editors. Water encyclopedia: the water quality and resource development. New York (NY): Wiley; p. 1-7. 
Paterson RR, Lima N. 2010. Toxicology of mycotoxins. EXS. 100:31-63.

Peeters E, Nelis HJ, Coenye T. 2008. Comparison of multiple methods for quantification of microbial biofilms grown in microtiter plates. J Microbiol Methods. 72:157-165.

Pettit RK, Weber CA, Pettit GR. 2009. Application of a high throughput Alamar blue biofilm susceptibility assay to Staphylococcus aureus biofilms. Ann Clin Microbiol Antimicrob. 8:28. doi: 10.1186/1476-0711-8-28.

Pitts B, Hamilton MA, Zelver N, Stewart PS. 2003. A microtiter-plate screening method for biofilm disinfection and removal. J Microbiol Methods. 54:269-276.

Pompilio A, Piccolomini R, Picciani C, D'Antonio D, Savini V, Bonaventura GD. 2008. Factors associated with adherence to and biofilm formation on polystyrene by Stenotrophomonas maltophila: the role of cell surface hydrophobicity and motility. FEMS Microbiol Lett. 287:41-47.

Priegnitz B-E, Wargenau A, Brandt U, Rohde M, Dietrich S, Kwade A, Krull R, Fleißner A. 2012. A role of initial spore adhesion in pellet and biofilm formation in Aspergillus niger. Fungal Genet Biol. 49:30-38.

Ramage G, Rajendran R, Gutierrez-Correa M, Jones B, Williams C. 2011. Aspergillus biofilms: clinical and indus- trial significance. FEMS Microbiol Lett. 324:89-97.

Ramage G, Vandewalle K, Wickes BL, Lopez-Ribot JL. 2001. Characteristics of biofilm formation by Candida albicans. Rev Iberoam Mic. 18:163-170.

Rampersad SN. 2012. Multiple applications of alamar blue as an indicator of metabolic function and cellular health in cell viability bioassays. Sensors. 12:12347-12360.

Ribeiro A, Machado AP, Kozakiewicz Z, Ryan M, Luke B, Buddie AG, Venâncio A, Lima N, Kelly J. 2006. Fungi in bottled water: a case study of a production plant. Rev Iber- oam Micol. 23:139-144.

Romanova NA, Gawande PV, Brovko LY, Griffiths MW. 2007. Rapid methods to assess sanitizing efficacy of benzalkonium chloride to Listeria monocytogenes biofilms. J Microbiol Methods. 71:231-237.

Sammon NB, Harrower KM, Fabbro LD, Reed RH. 2011. Three potential sources of microfungi in a treated municipal water supply system in subtropical Australia. Int J Environ Res Public Health. 8:713-732.

Sarker SD, Nahar L, Kumarasamy Y. 2007. Microtitre plate- based antibacterial assay incorporating resazurin as an indicator of cell growth, and its application in the in vitro antibacterial screening of phytochemicals. Methods. 42:321e324.

Schwartz DS, Larsh HW, Bartels PA. 1977. Enumerative fluorescent vital staining of live and dead pathogenic yeast cells. Stain Technol. 52:203-210.

Simões LC. 2013. Biofilms in drinking water. In: Simões M, Mergulhão F, editors. Biofilms in bioengineering. New York (NY): Nova Science; p. 157-189. ISBN: 978-1- 62948-161-6.

Simões LC, Simões M. 2013. Biofilms in drinking water: problems and solutions. RSC Adv. 3:2520-2533.

Simões LC, Simões M, Oliveira R, Vieira MJ. 2007. Potential of the adhesion of bacteria isolated from drinking water to materials. J Basic Microbiol. 47:174-183.

Simões LC, Simões M, Vieira MJ. 2007. Biofilm interactions between distinct bacterial genera isolated from drinking water. Appl Environ Microbiol. 73:6192-6200.

Simões LC, Simões M, Vieira MJ. 2010a. Adhesion and bio- film formation on polystyrene by drinking water-isolated bacteria. Anton Leeuw Int J G. 98:317-329. 
Simões LC, Simões M, Vieira MJ. 2010b. Influence of the diversity of bacterial isolates from drinking water on resistance of biofilms to disinfection. Appl Environ Microbiol. 76:66736679.

Simões LC, Simões M, Vieira MJ. 2011. The effects of metabolite molecules produced by drinking water-isolated bacteria on their single and multispecies biofilms. Biofouling. 27:685699.

Singh R, Shivaprakash MR, Chakrabarti A. 2011. Biofilm formation by zygomycetes: quantification, structure and matrix composition. Microbiology. 157:2611-2618.

Siqueira VM, Lima N. 2013. Biofilm formation by filamentous fungi recovered from a water system. J Mycol. 2013:Article ID 152941, 9p.

Siqueira VM, Oliveira HMB, Santos C, Paterson RRM, Gusmão NB, Lima N. 2011. Filamentous fungi in drinking water, particularly in relation to biofilm formation. Int J Environ Res Public Health. 8:456-469.

Siqueira VM, Oliveira HMB, Santos C, Paterson RRM, Gusmão NB, Lima N. 2013. Biofilms from a Brazilian water distribution system include filamentous fungi. Can $\mathrm{J}$ Microbiol. 59:183-188.

Snelling WJ, Moore JE, McKenna JP, Lecky DM, Dooley JSG. 2006. Bacterial-protozoa interactions: an update on the role these phenomena play towards human illness. Microbes Infect. 8:578-587.

Szewzyk U, Szewzyk R, Manz W, Schleifer KH. 2000. Microbiological safety of drinking water. Ann Rev Microbiol. 54:81-127.

Traganos F, Darzynkiewicz Z, Sharpless T, Melamed MR. 1977. Simultaneous staining of ribonucleic and deoxyribonucleic acids in unfixed cells using acridine orange in a flow cytofluorometric system. J Histochem Cytochem. 25:46-56.

Villena GK, Fujikawa T, Tsuyumu S, Gutiérrez-Correa M. 2010. Structural analysis of biofilms and pellets of Aspergillus niger by confocal laser scanning microscopy and cryo scanning electron microscopy. Bioresour Technol. 101:1920-1926.

Villena GK, Gutierrez-Correa M. 2007. Morphological patterns of Aspergillus niger biofilms and pellets related to ligno- cellulolytic enzyme productivities. Lett Appl Microbiol. 45:231-237.

Wösten HAB. 2001. Hydrophobins: multipurpose proteins. Annu Rev Microbiol. 55:625646. 


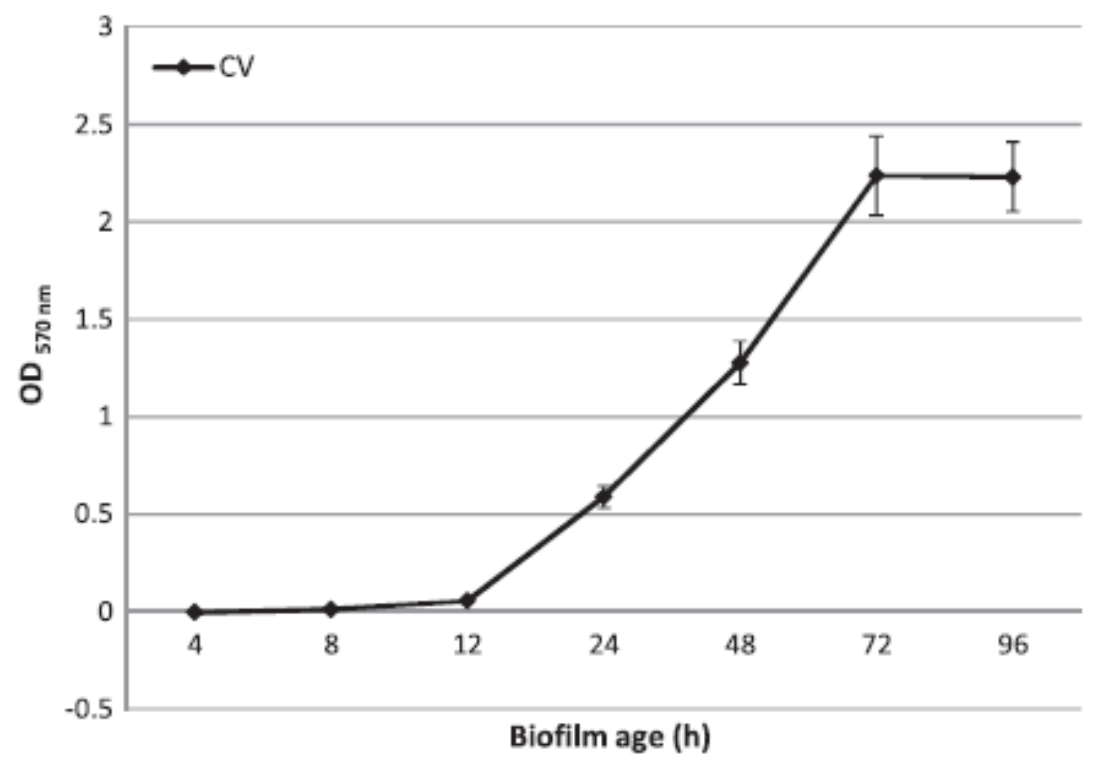

Figure 1. Fungal biofilm formation over time in terms of bio- mass assessed by CV staining. The means \pm SDs for at least three replicates are illustrated.

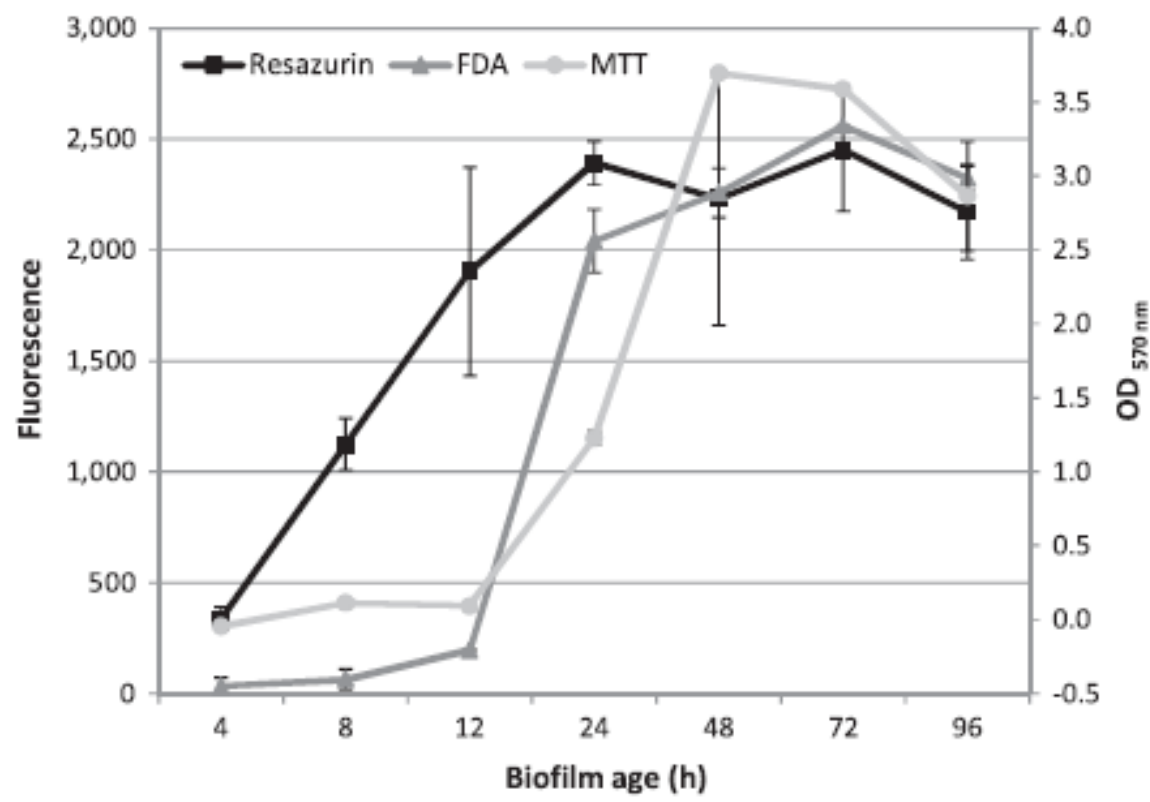

Figure 2. Fungal biofilm formation over time in terms of metabolic activity assessed by resazurin, FDA, and MTT staining. The means \pm SDs for at least three replicates are illustrated. 


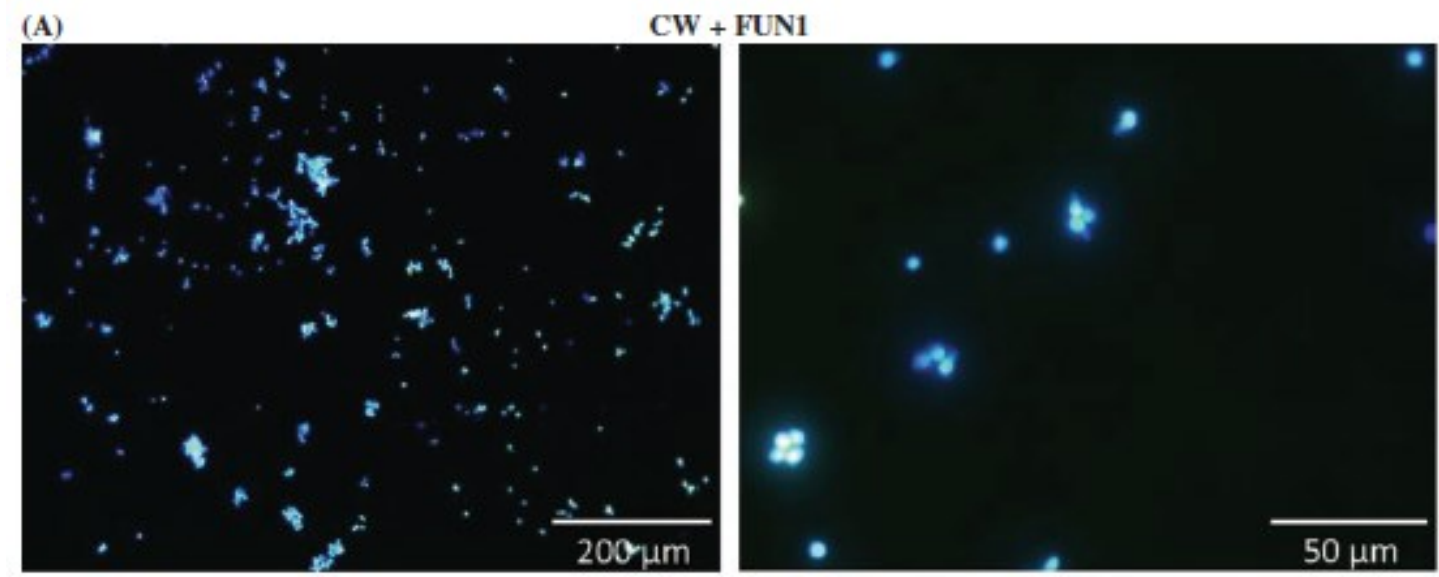

(B)

CW + FDA
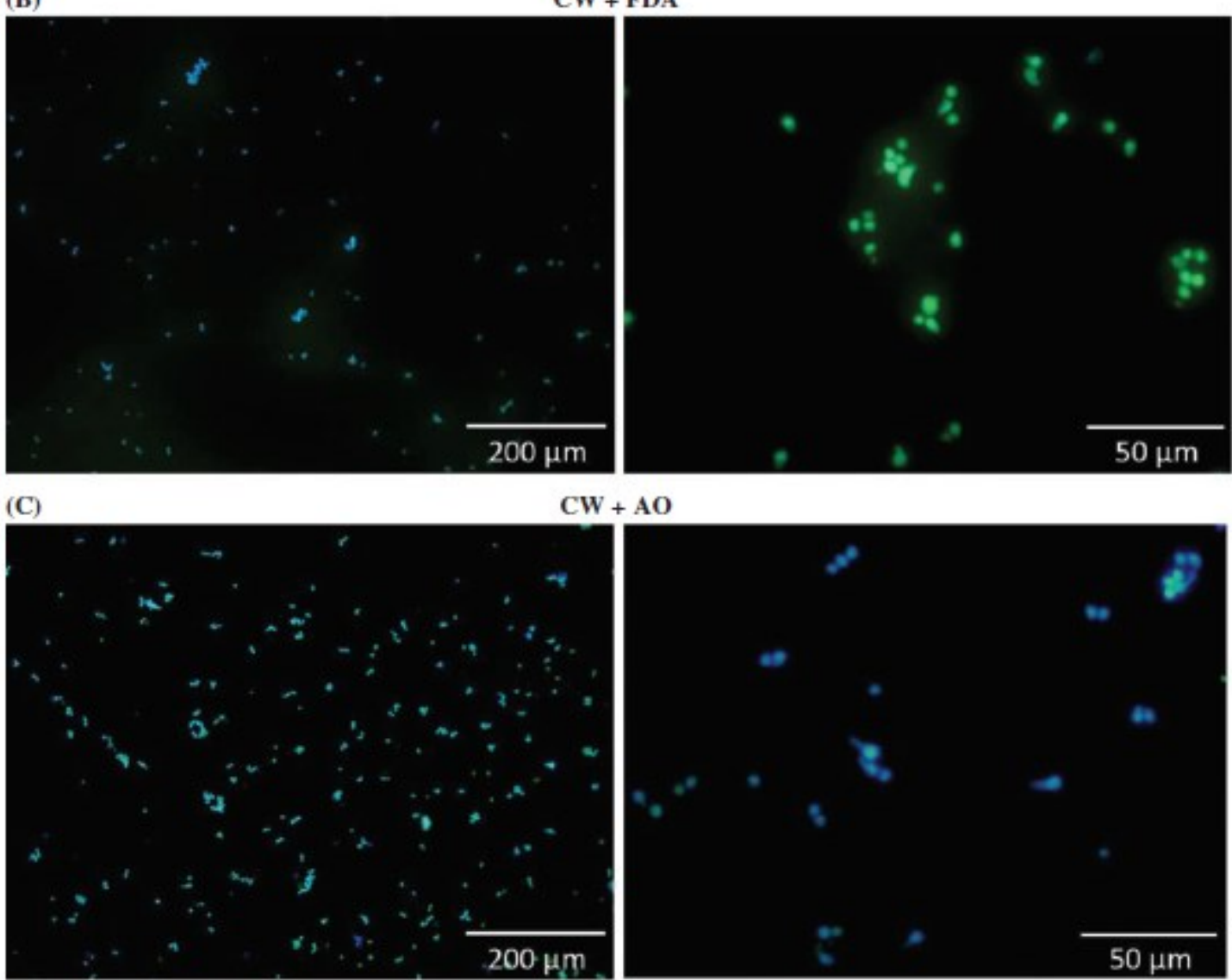

Figure 3. Epifluorescence photomicrographs of spores adhered $(8 \mathrm{~h})$ to polystyrene with several fluorochrome combinations: (A) CW plus FUN-1; (B) CW plus FDA; (C) CW plus AO. $\times 100$ magnification $/$ bar $=200 \mu \mathrm{m} ; \times 400$ magnification $/$ bar $=50 \mu \mathrm{m}$. 

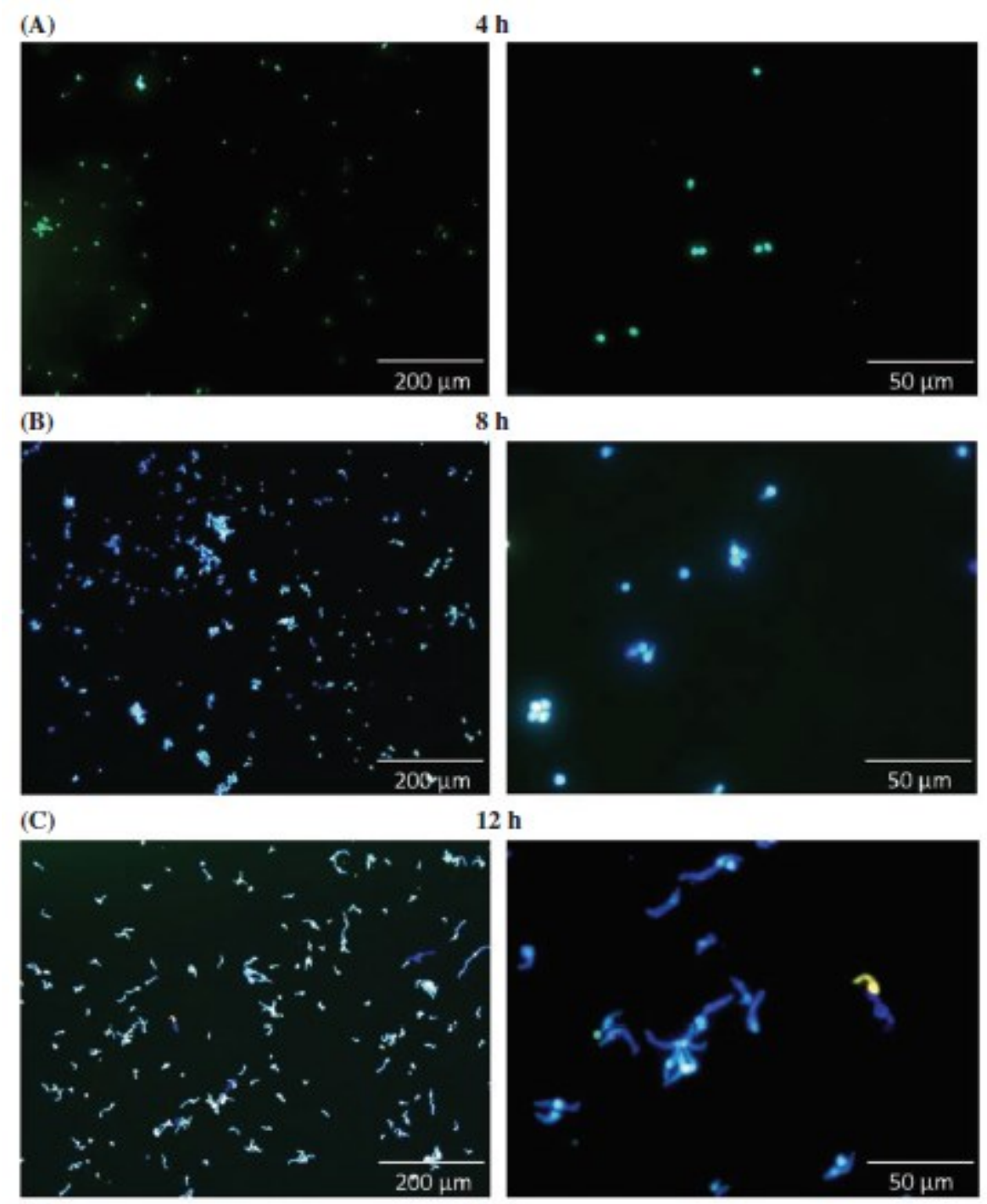

(D)

$24 \mathrm{~h}$

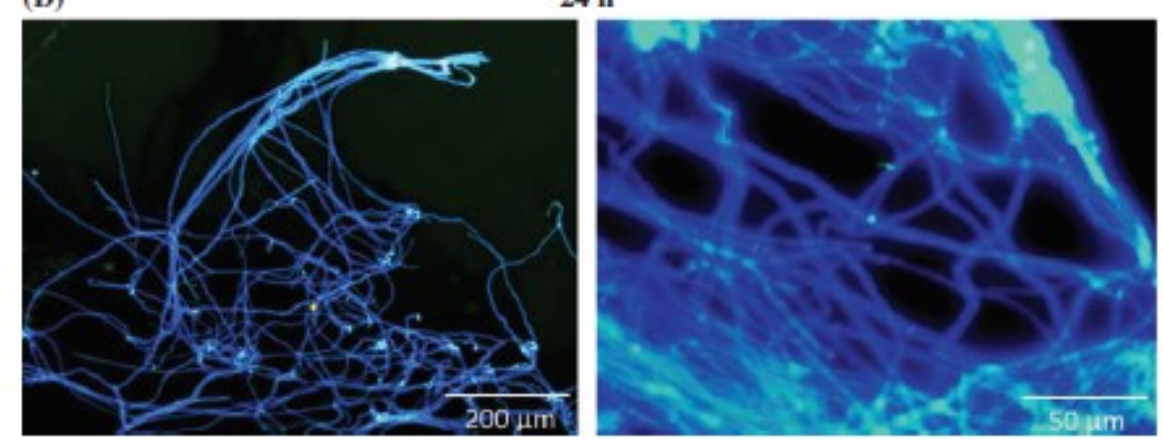


(E) $48 \mathrm{~h}$

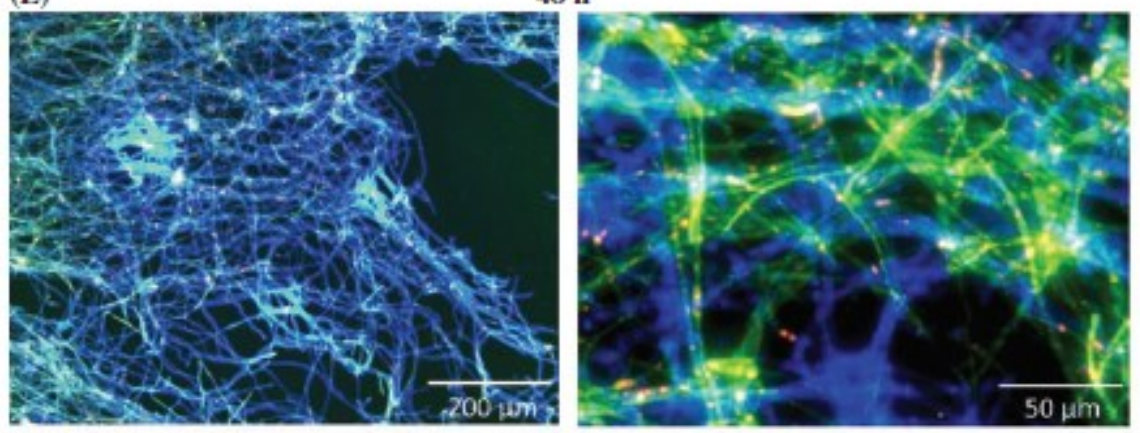

(F)

$72 \mathrm{~h}$
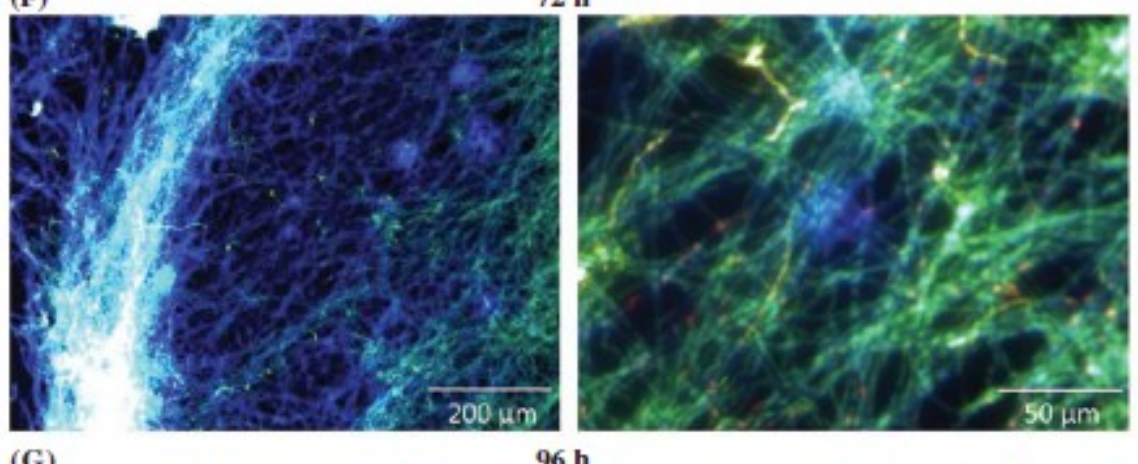

(G)

$6 \mathrm{~h}$
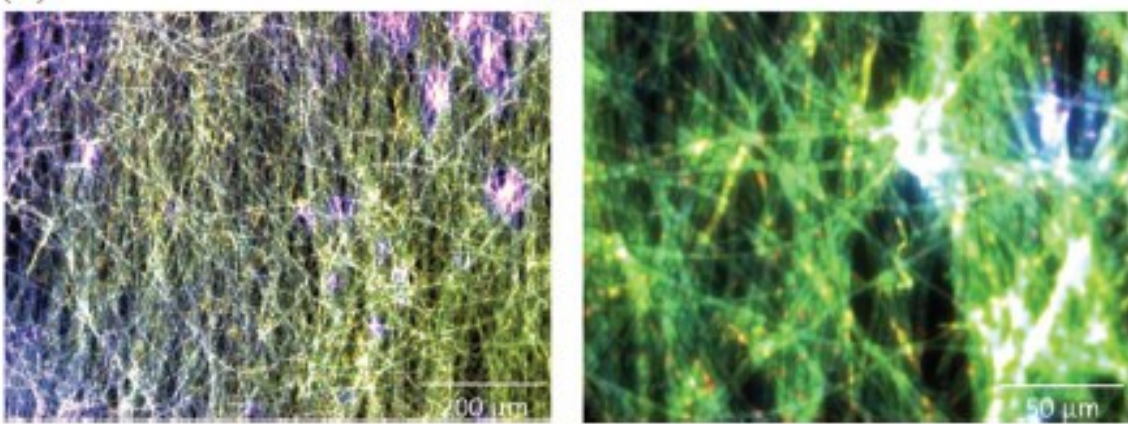

Figure 4. Epifluorescence photomicrographs of fungal biofilm formation on polystyrene over time with CW plus FUN-1: (A) 4 h, 8 h, (C) 12 h, (D) 24 h, (E) 48 h, (F) $72 \mathrm{~h}$ and (G) 96 h. $\times 100$ magnification $/ \mathrm{bar}=200 \mu \mathrm{m} ; \times 400$ magnification $/ \mathrm{bar}=50 \mu \mathrm{m}$. 

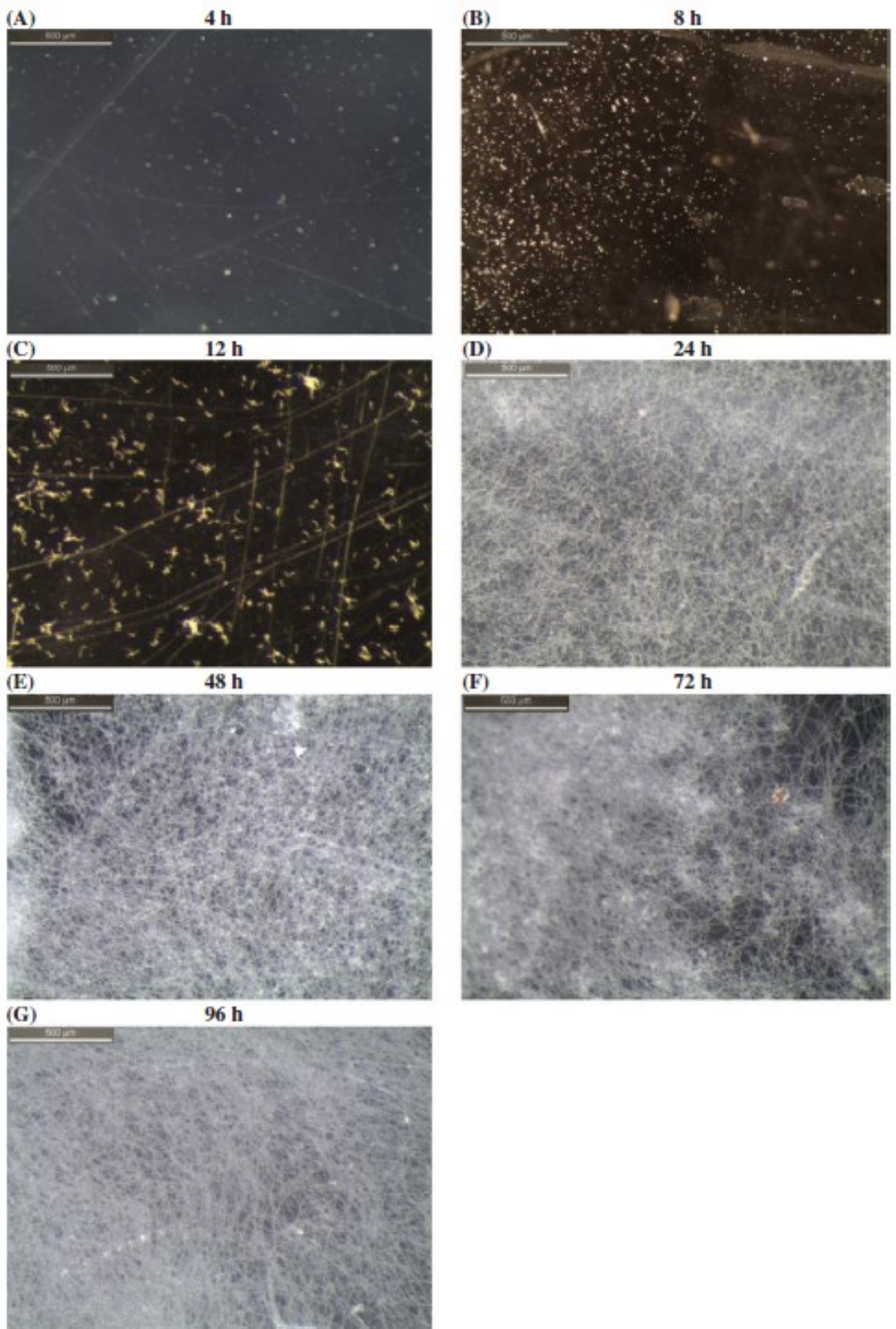

Figure 5. Bright-field photomicrographs of fungal biofilm formation on polystyrene over time: (A) $4 \mathrm{~h}$, (B) $8 \mathrm{~h}$, (C) $12 \mathrm{~h}$, (D) $24 \mathrm{~h}$, (E) $48 \mathrm{~h}$, (F) $72 \mathrm{~h}$ and (G) $96 \mathrm{~h} . \times 50$ magnification/bar $=500$ $\mu \mathrm{m}$. 